\title{
Strategies for the determination of the convective-diffusion limiting current from steady state linear sweep voltammetry
}

\author{
C. Ponce-de-León · C. T. J. Low · G. Kear · \\ F. C. Walsh
}

Received: 14 December 2006/Revised: 20 July 2007 / Accepted: 26 July 2007

(C) Springer Science+Business Media B.V. 2007

\begin{abstract}
The limiting current is an important parameter for the characterization of mass transport in electrochemical systems operating under convective-diffusion control. Four methods to determine the limiting current from current $(I)$ vs. potential $(E)$ plots are considered. Strategies to determine the limiting current values include: (1) direct measurement from $I$ vs. $E$ curves, (2) estimation from the current value at $E_{\mathrm{L}}=\Delta E / 2$ where $\Delta E$ is the length of the limiting current plateau, (3) evaluation of the first derivative $\mathrm{d} I / \mathrm{d} E$ in the $I$ vs. $E$ curve and (4) from plots of $E / I$ vs. $I^{-1}$. The electrode reactions chosen to demonstrate the different strategies are: $\mathrm{Cu}(\mathrm{II}) \rightarrow \mathrm{Cu}(\mathrm{I})$ and $\mathrm{Cu}(\mathrm{I}) \rightarrow$ $\mathrm{Cu}(0)$ in $1.5 \mathrm{~mol} \mathrm{dm}{ }^{-3} \mathrm{NaCl}(\mathrm{pH} 2)$ at a platinum rotating disc electrode and $\mathrm{Fe}(\mathrm{CN})_{6}^{3-} \rightarrow \mathrm{Fe}(\mathrm{CN})_{6}^{4-}$ in $1 \mathrm{~mol} \mathrm{dm}^{-3}$ $\mathrm{NaOH}$ at a 60 ppi reticulated vitreous carbon electrode (RVC).
\end{abstract}

Keywords Copper deposition - Ferricyanide . Mass transport · Limiting current · Polarization curves . Voltammetry $\cdot$ Reticulated vitreous carbon .

Rotating disc electrode

C. Ponce-de-León $(\bowtie) \cdot$ C. T. J. Low · F. C. Walsh Electrochemical Engineering Laboratory, Energy Technology Research Group, School of Engineering Sciences, University of Southampton, Highfield, Southampton SO17 1BJ, UK

e-mail: capla@soton.ac.uk

G. Kear

Building Research Association of New Zealand (BRANZ) Ltd, Private Bag 50 908, Porirua City 6220, New Zealand

Present Address:

G. Kear

Electrochemical Engineering Laboratory, Energy Technology, Research Group, School of Engineering Sciences, University of Southampton, Highfield, Southampton SO17 1BJ, UK
Notation

Symbol

A Electrode area $\left(\mathrm{cm}^{2}\right)$

$c_{\mathrm{b}} \quad$ Concentration of reactant ions in the bulk solution $\left(\mathrm{mol} \mathrm{dm}{ }^{-3}\right)$

$E_{1 / 2} \quad$ Half-wave potential, corresponding to $I_{\mathrm{L}} / 2(\mathrm{~V})$

$E_{\mathrm{L}} \quad$ Potential at which the limiting current value is taken $(\mathrm{V})$

$E_{\max }$ Maximum potential value on the plateau region (V)

$E_{\min } \quad$ Minimum potential value on the plateau region (V)

$F \quad$ Faraday constant, $96,485\left(\mathrm{C} \mathrm{mol}^{-1}\right)$

$D \quad$ Diffusion coefficient of electroactive species $\left(\mathrm{cm}^{2} \mathrm{~s}^{-1}\right)$

I Current (mA)

$I_{\mathrm{L}} \quad$ Limiting current $(\mathrm{mA})$

$j_{\mathrm{L}} \quad$ Limiting current density $\left(\mathrm{mA} \mathrm{cm}^{-2}\right)$

$k_{\mathrm{m}} \quad$ Mass transport coefficient $\left(\mathrm{cm} \mathrm{s}^{-1}\right)$

$z \quad$ Number of electrons transferred in the reaction (Dimensionless)

$v \quad$ Mean linear velocity of the electrolyte $\left(\mathrm{cm} \mathrm{s}^{-1}\right)$

$\omega \quad$ Rotation rate of disc electrode $\left(\mathrm{rad} \mathrm{s}^{-1}\right)$

$v \quad$ Kinematic viscosity of the electrolyte $\left(\mathrm{cm}^{2} \mathrm{~s}^{-1}\right)$

\section{Introduction}

Mass transport measurements can be carried out in several ways in electrochemical reactor geometries, parallel plate electrodes, rotating and three-dimensional porous electrodes [1]. These reactors often operate under (complete or partial) mass transport control due to the restricted rate of convective-diffusion of reactant to the electrode surface. Application areas of electrochemical technology which involve mass transport control includes electrosynthesis, effluent treatment and metal recovery [2]. 
The limiting current is an important parameter for the characterization of mass transport rates in electrochemical systems. When an electrochemical system operates under limiting current conditions, the reaction proceeds at the maximum rate and hydrodynamic properties can be characterized, facilitating comparison with other electrochemical systems. Mass transport coefficients $\left(k_{\mathrm{m}}\right)$ for certain redox couples calculated from the limiting current values are frequently used in order to characterise the mass transport conditions of electrochemical cells and reactors [2-4].

The redox couples typically employed to characterize mass transport rates in electrochemical reactors are: $\mathrm{Fe}(\mathrm{CN})_{6}^{4-} / \mathrm{Fe}(\mathrm{CN})_{6}^{3-}$ and $\mathrm{Cu}^{2+} / \mathrm{Cu}^{0}$. For example Wragg et al. have used the limiting current technique during the reduction of ferricyanide ion at nickel minielectrodes to map the two-dimensional mass transport coefficient distribution in a small cell operated with and without baffles $[5,6]$. The cell without baffles contained a dead zone in the centre while the baffled cell exhibited larger mass transport coefficients. In another work, the limiting diffusion current technique was used to evaluate the free convective mass transport rates at thin copper disks having different diameters and inclinations. The reduction of copper ion in acid sulphate was used as the electrochemical system [7]. Additional examples of the use of the limiting current technique include the reduction of ferricyanide ion to characterize the mass transport performance of the FM21-SP filter-press reactor used in the chlor-alkali industry $[8,9]$ and the characterization of a crossflow corrugated membrane reactor, developed for a number of electrochemical processes [10]. The deposition of copper ions has recently been used to characterize the mass transport properties of a spinning disc electrochemical reactor [11]. Other redox systems commonly used to calculate the limiting current include: $\mathrm{O}_{2} /$ $\mathrm{OH}^{-}, \mathrm{I}_{3}^{-} / \mathrm{I}^{-}, \mathrm{Fe}^{3+} / \mathrm{Fe}^{2+}, \mathrm{Ag}^{+} / \mathrm{Ag}^{0}$ and $\mathrm{Ce}^{4+} / \mathrm{Ce}^{3+}$.

Determination of the limiting current is also important in the evaluation of electrodialysis during desalination processes $[12,13]$ and in metal separation and electrodissolution [14, 15]. Many amperometric sensors operate under limiting current conditions, making the correct estimation of the limiting current value essential for calibration purposes [16].

\section{Factors affecting the limiting current}

The limiting current condition arises when the electroactive species in the diffusion boundary layer reacts immediately on contact with the electrode or, in the case of an electrodialysis process, the charged species sinks through the ionic channels of an ion exchange membrane as soon as it contacts its surface. Under these conditions, the current is limited by the rate at which the electroactive species reaches the surface. In an electrochemical process, the definition of the limiting current is when the change of current with potential is minimum or zero, i.e., $\mathrm{d}(I) / \mathrm{d}(E)=0$ [17]. During the reduction of metal ions, the limiting current is achieved when the concentration of an electroactive species at the electrode surface is negligible [18] and:

$I_{\mathrm{L}}=z F k_{\mathrm{m}} A c_{\mathrm{b}}$

where $I_{\mathrm{L}}$ is the limiting current, $z$ is the number of electrons transferred, $F$ is the Faraday constant, $k_{\mathrm{m}}$ is the mass transport coefficient, $A$ is the electrode area and $c_{\mathrm{b}}$ is the concentration of the electroactive species in the bulk solution. Theoretical considerations of the limiting current conditions for a variety of electrochemical systems have been published in detail elsewhere. Among the most cited works analysing the use of the limiting current for mass transport are those published by Selman and Tobias [18] and Tobias et al. [19], the latter involving a smooth rotating cylinder electrodes (RCE). Typically, the limiting current value is taken from the plateau region in a current vs. potential curve. However, a significant slope in the limiting current region can make such measurements difficult and inaccurate. The limiting current region can be affected by factors such as the secondary reaction, electrolyte composition (including $\mathrm{pH}$ ), increase of the electrode area due to metal deposition, changes in the concentration of the electroactive species and uneven current and/or potential distribution. Additionally, the plateau region can be affected by charge transfer effects when the mixed control region extends towards the limiting current region, as in the case of slow and irreversible reactions [4]. In the mixed control region, the overall reaction is influenced by both charge transfer and mass transport control of the electrochemical reaction [2-4].

The calculation of the limiting current value in a flat and horizontal plateau region is, in principle, simple; the main electrochemical reaction is well separated from charge transfer effects and from a secondary reaction, usually hydrogen evolution in a reduction process. A plateau region extended over a large potential range indicates that the limiting current value is not affected by the mixed control region of the primary reaction and from the current generated from the secondary reaction. In some cases, however, the potential span of the plateau region is less than $0.2 \mathrm{~V}$ and a poorly defined plateau region may exist when both primary and secondary reactions occur at similar potentials or where the mixed control region extends close to the potential of the secondary reaction. Figure 1 shows an schematic diagram of both an ideal and non-ideal reduction processes, indicating the charge transfer, mixed and mass transport control regions and the secondary reaction. 


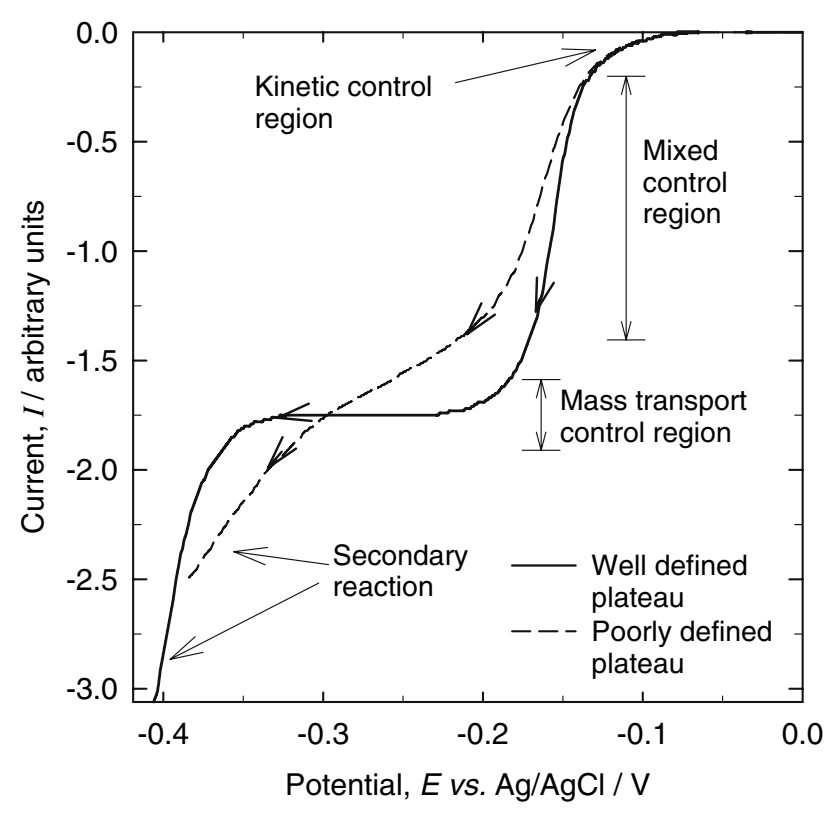

Fig. 1 Schematic current vs. potential behaviour showing the charge transfer, mixed and mass transport controlled regions and the secondary reaction for well defined and poorly defined plateaux regions

In this paper strategies for the estimation of the limiting current will be presented. The reduction of $\mathrm{Cu}(\mathrm{II})$ ions to $\mathrm{Cu}(0)$ in chloride media will be used as a main example and the reduction of $\mathrm{Fe}(\mathrm{CN})_{6}^{-3}$ in sodium hydroxide at a $10 \mathrm{ppi}$ RVC electrode fitted in the FM01-LC cell. These reactions were chosen because they present two- single (copper) and one- (ferricyanide) electron reduction waves, respectively, and they are commonly used to determine the limiting current of different systems in the literature. The strategies are:

1. Direct visual measurement of $I_{\mathrm{L}}$ from $I$ vs. $E$ curves,

2. Estimation from the value of $E_{\mathrm{L}}=\left(E_{\max }-E_{\min }\right) / 2$, were $E_{\max }$ and $E_{\min }$ are the maximum and minimum values of potential on the plateau region of the $I$ vs. $E$ curve; the limiting current value is taken at the $E_{\mathrm{L}}$ value,

3. From the evaluation of the derivative $\mathrm{d} I / \mathrm{d} E$ plotted against the applied potential, $E$ and

4. From the plots of $E / I$, vs. the reciprocal of the current, $I^{-1}$.

\section{Experimental details}

\section{1 $\mathrm{Cu}(\mathrm{II}) / \mathrm{Cu}(0)$ system}

A typical, three-compartment electrochemical cell of $100 \mathrm{~mL}$ volume was used for the copper deposition experiments. The cell was constructed with a double wall to allow circulation of water maintaining the temperature of the electrolyte constant. The rotating disc electrode faces the bottom of the cell and its potential was monitored by a silver/silver chloride reference electrode (ABB Instrumentation Ltd) placed in a separate compartment and connected to the cell via a Luggin capillary. The counter electrode was a platinum mesh placed in a different compartment separated from the rest of the solution by a porous glass frit. The potentiostat and the linear potential sweep unit were Hitek DT2101 and PPR1 waveform generator, respectively. The XY recorder was a PL3 from Seatallan Ltd. The supporting electrolyte consisted of $1.5 \mathrm{~mol} \mathrm{dm}^{-3}$ $\mathrm{NaCl}$ at $\mathrm{pH} 2$ and contained $2 \times 10^{-3} \mathrm{~mol} \mathrm{dm}^{-3}$ of $\mathrm{Cu}$ (II) ions prepared using $\mathrm{CuCl}_{2}$, all the reagents were analytical grade from Fisher Chemicals. Before each voltammogram, the working electrode $\left(0.42 \mathrm{~cm}^{2}\right.$ platinum disc $)$ was manually polished with wet alumina powder on a surface cloth and rinsed with deionised water until its surface was clean to the eye. The solution was purged with high purity nitrogen gas for $5 \mathrm{~min}$ before each experiment in order to deoxygenate the solution and to avoid interference from the oxygen reduction reaction. The nitrogen supply was maintained over the surface of the electrolyte during the course of the experiments and it was replaced into the solution while the working electrode was polished. The rotation rates employed were between 150 and $1,870 \mathrm{rpm}$ (2.5-31.2 Hz; 16-196 $\left.\mathrm{rad} \mathrm{s}^{-1}\right)$ and the potential was linearly swept from +0.70 to $-0.60 \mathrm{~V}$ vs. $\mathrm{Ag} / \mathrm{AgCl}$ at a scan rate of $10 \mathrm{mV} \mathrm{s}^{-1}$. The experimental procedures are described in detail elsewhere [20].

\section{$3.2 \mathrm{Fe}(\mathrm{CN})_{6}^{-3} / \mathrm{Fe}(\mathrm{CN}){ }_{6}^{-4}$ system}

The reduction of ferricyanide was carried out on a 10 ppi RVC electrode mounted in the FM01-LC electrolyser in the undivided mode. A full description of this cell is available in the literature [21-23]. The concentration of ferricyanide ion was $1 \times 10^{-2} \mathrm{~mol} \mathrm{dm}^{-3}$ in $1 \mathrm{~mol} \mathrm{dm}^{-3}$ of $\mathrm{NaOH}$ and the electrolyte contained $5 \times 10^{-2} \mathrm{~mol} \mathrm{dm}^{-3}$ of ferrocyanide ion to ensure that the rate of the anodic process (oxidation of ferrocyanide to ferricyanide ion) did not limit the total reaction. The mean linear flow rate of the electrolyte was varied between 0.062 and $0.195 \mathrm{~m} \mathrm{~s}^{-1}$ at $25{ }^{\circ} \mathrm{C}$. The electrolyte was contained in a $1.5 \mathrm{dm}^{3}$ glass reservoir and was circulated through the cell with a magnetically coupled, centrifugal pump. Details of this experiment can be found in the literature [24].

\section{Evaluation of the limiting current for the $\mathrm{Cu}(\mathrm{II}) / \mathrm{Cu}(0)$ system}

Figure 2 shows $I$ vs. $E$ curves for the reduction of $2 \times 10^{-3} \mathrm{~mol} \mathrm{dm}^{-3} \mathrm{Cu}(\mathrm{II})$ to $\mathrm{Cu}(0)$ in $1.5 \mathrm{~mol} \mathrm{dm}^{-3}$ 
$\mathrm{NaCl}$ at $\mathrm{pH} 2$ at a platinum rotating disc electrode (RDE). In chloride electrolytes, the reduction of $\mathrm{Cu}(\mathrm{II})$ ions occurs in two single electron steps and the reactions can be simplified to the reduction of $\mathrm{Cu}$ (II) ions to $\mathrm{Cu}(\mathrm{I})$ ions [20]:

$\mathrm{Cu}^{2+}+2 \mathrm{Cl}^{-}+e^{-} \rightarrow \mathrm{Cu}^{\mathrm{I}} \mathrm{Cl}_{2}^{-}$

followed by the deposition of metallic copper from the $\mathrm{Cu}(\mathrm{I})$ ions, i.e.:

$\mathrm{Cu}^{\mathrm{I}} \mathrm{Cl}_{2}^{-}+e^{-} \rightarrow \mathrm{Cu}^{0}+2 \mathrm{Cl}^{-}$

The overall process for copper deposition from $\mathrm{Cu}(\mathrm{II})$ ions then is:

$\mathrm{Cu}^{2+}+2 e^{-} \rightarrow \mathrm{Cu}^{0}$

The curves in Fig. 2 show the reduction processes corresponding to reactions (2) and (3). For the lowest rotation rate, $150 \mathrm{rpm},\left(\omega_{1}=16 \mathrm{rad} \mathrm{s}^{-1}\right)$, the reduction of $\mathrm{Cu}(\mathrm{II})$ to $\mathrm{Cu}(\mathrm{I})$, starts at approximately $+0.390 \mathrm{~V}$ vs. $\mathrm{Ag} /$ $\mathrm{AgCl}$ with an approximate $E_{1 / 2}$ of $0.280 \mathrm{~V}$ vs. $\mathrm{Ag} / \mathrm{AgCl}$. The $E_{1 / 2}$ value is the potential on the voltammetric curve where the current is half of the limiting current [25]. The reduction is observed as a constant current plateau region at each rotation rate $\omega$, since the continuous rotation of the electrode maintains a constant supply of $\mathrm{Cu}(\mathrm{II})$ to the electrode surface. A peak instead of a plateau would be observed if the electrode was static [20]. As the electrode potential becomes more negative, the reduction of $\mathrm{Cu}(\mathrm{I})$,

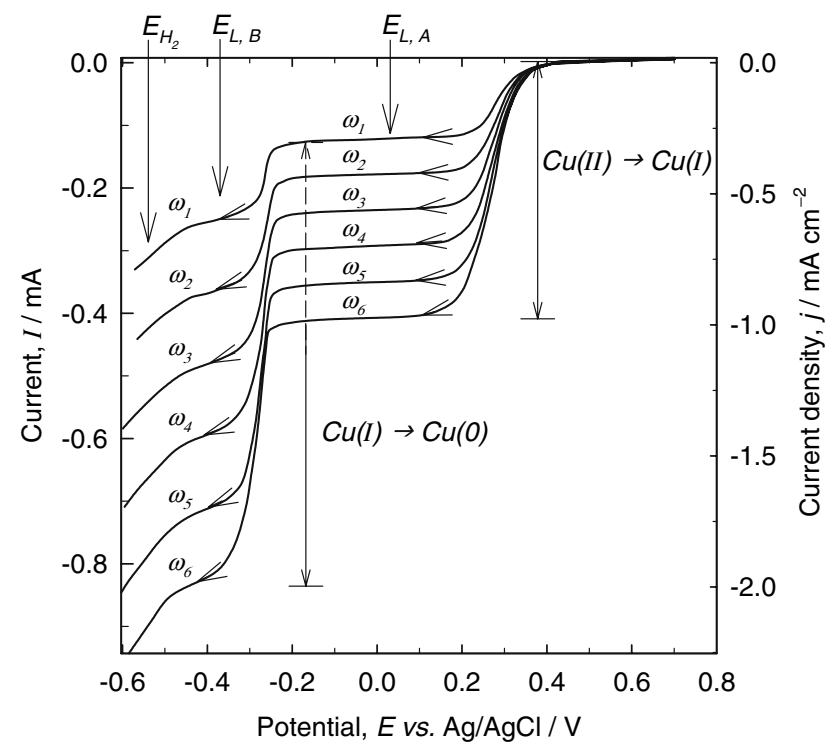

Fig. 2 Reduction of $2 \times 10^{-3} \mathrm{~mol} \mathrm{dm}^{-3} \mathrm{CuCl}_{2}$ in $1.5 \mathrm{~mol} \mathrm{dm}^{-3}$ $\mathrm{NaCl}, \mathrm{pH} 2$ at $20^{\circ} \mathrm{C}$ at a Pt RDE (area $=0.42 \mathrm{~cm}^{2}$ ) using a potential sweep rate of $10 \mathrm{mV} \mathrm{s}^{-1}$. Rotation rates: $\omega_{1}=16, \omega_{2}=36, \omega_{3}=64$, $\omega_{4}=100, \omega_{5}=144$ and $\omega_{6}=196 \mathrm{rad} \mathrm{s}^{-1}$ appears at a potential of approximately $-0.24 \mathrm{~V}$ vs. Ag/ $\mathrm{AgCl}$. The second plateau is less well defined as it is affected by the reduction of hydrogen. At this potential ( $\approx-0.5 \mathrm{~V}$ vs. $\mathrm{Ag} / \mathrm{AgCl}$ ) the reactions (2) and (3) take place simultaneously; the rotation of the electrode brings $\mathrm{Cu}(\mathrm{II})$ from the bulk of the solution to the electrode surface which is immediately reduced to $\mathrm{Cu}(\mathrm{I})$ and then to $\mathrm{Cu}(0)$. Under these conditions, the total current is the sum of the processes corresponding to each of the electrode reactions (2) and (3). Each plateau region is characterised by a limiting current value, which is proportional to the rate at which the reactant species reach the electrode surface. Under such conditions, the reaction rate is limited by the mass transport rate and the limiting current at the smooth rotating disc in laminar flow can be predicted by the Levich equation [2-4]:

$I_{\mathrm{L}}=0.620 z \mathrm{FAD}^{2 / 3} \omega^{1 / 2} v^{-1 / 6} c_{\mathrm{b}}$

where $I_{\mathrm{L}}$ is the limiting current in $\mathrm{mA}, D$ is the diffusion coefficient in $\mathrm{cm}^{2} \mathrm{~s}^{-1}, \omega$ is the rotation rate in $\mathrm{rad} \mathrm{s}^{-1}$ and $v$ is the kinematic viscosity of the electrolyte in $\mathrm{cm}^{2} \mathrm{~s}^{-1}$. At higher rotation rates, $\omega>150 \mathrm{rpm}\left(>16 \mathrm{rad} \mathrm{s}^{-1}\right)$, the $I-E$ curves have a similar shape and the supply of electroactive species to the electrode surface is faster resulting in higher limiting currents. In Eq. 5, the number of electrons, $z$, is 1 if the reactions (2) and (3) occur consecutively, in other electrolyte media such as sulphate, the two processes cannot be distinguished and the reduction of $\mathrm{Cu}$ (II) to $\mathrm{Cu}(0)$ appears as a single step where the number of electrons $z$, used in Eq. 5 is 2 .

\section{Estrategies to calculate limiting current values from $I$ vs. $E$ curves}

\subsection{Direct estimation of the limiting current from $I$ vs. $E$ curves}

The direct estimation of the limiting current can be made by taking the middle point of a straight line on the plateau region which is limited by two lines at both sides of the plateau. The two lines at both sides of the plateau (dashed lines on Fig. 3) follow the mixed control region and the secondary reaction, respectively. The method is shown for the two reduction waves in Fig. 3 when the electrode rotated at $\omega_{4}=100 \mathrm{rad} \mathrm{s}^{-1}$. As mentioned earlier, the secondary reaction for reaction (3) is the $\mathrm{H}_{2}$ evolution but for reaction (2) the secondary reaction is reaction (3). This method is simple and accurate when the plateau region is well defined and not influenced by other factors as in the first reduction process $\mathrm{Cu}$ (II) to $\mathrm{Cu}$ (I). If the plateau region is affected by an increase in the electrode area or by the secondary reaction, accurate measurement of the limiting current value is more problematic. 


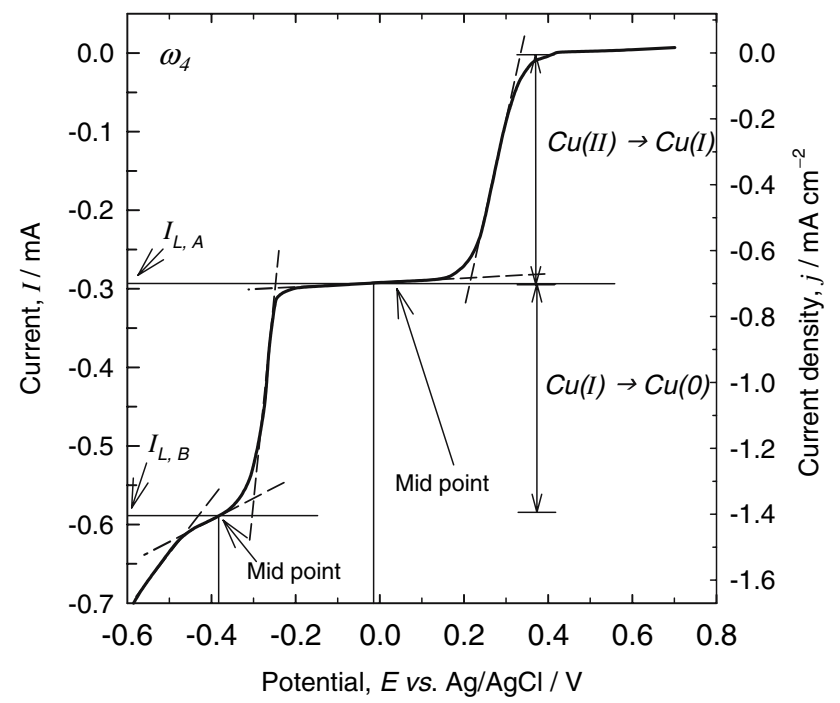

Fig. 3 A direct method to determine the limiting current values for reduction of; $\mathrm{Cu}$ (II) to $\mathrm{Cu}(\mathrm{I})$ and $\mathrm{Cu}(\mathrm{I})$ to $\mathrm{Cu}(0)$. The curve corresponds to a rotation rate of $\omega_{4}=100 \mathrm{rad} \mathrm{s}^{-1}$ in Fig. 2

\subsection{Limiting current value from $E_{\max }$ and $E_{\min }$ values}

In this procedure, the limiting current is found at the middle point of a straight line that follows the plateau region and is limited by $E_{\max }$ and $E_{\min }$ (see, for example, Gabe and Makanjuola [26]). These values are the points at which the straight line departs from the $I$ vs. $E$ curve, shown as dashed lines in Fig. 4. The method is graphically illustrated in the figure for the two reduction waves when the RDE rotated at $\omega_{4}=100 \mathrm{rad} \mathrm{s}^{-1}$. The $I_{\mathrm{L}}$ value is found by extrapolating the middle point on the straight line, i.e., $\left(E_{\max }-E_{\min }\right) /$ $2=\Delta E / 2$, to the current axis as shown in Fig. 4 .

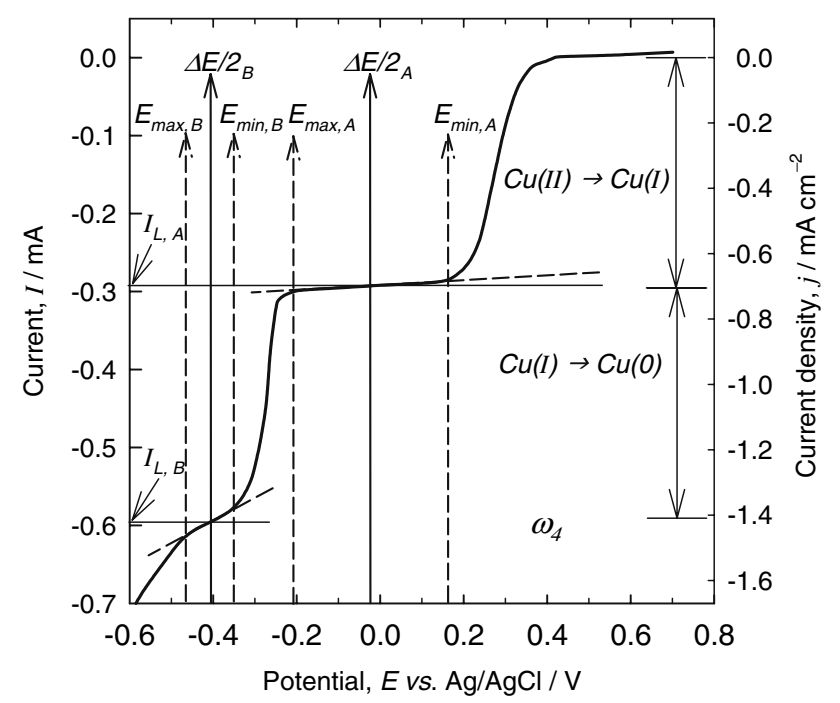

Fig. 4 Limiting current measured at the middle point of $E_{\min }$ and $E_{\max }$. Data for the reduction of $\mathrm{Cu}(\mathrm{II})$ ions from Fig. 2 at an RDE rotation of $100 \mathrm{rad} \mathrm{s}^{-1}$
This approach produces similar current values to the direct method when the plateau region is horizontal depending on the extension of both, the mixed control region and the secondary reaction. In the case of an illdefined plateau, the limiting current values can differ since visual identification of the maximum and minimum point can be subjective.

\subsection{Evaluation of $\mathrm{d} I / \mathrm{d} E$ vs. $E$ curves}

This procedure involves the evaluation of the derivative of the current vs. potential which is then plotted against the applied potential $E$. When the value of the derivative, $\mathrm{d} I /$ $\mathrm{d} E$, in absolute terms is maximum, indicates a point of inflexion in the $I$ vs. $E$ curve; this is the case on the mixed control region where the derivative produces a peak. In the limiting current region the derivative $\mathrm{d} I / \mathrm{d} E$ should be zero.

Figure 5 shows a plot of the absolute values of the derivative vs. the applied potential taken from the $I$ vs. $E$ curves shown in Fig. 2. The two peaks correspond to the points at which the slope of the current potential curve changes direction on the mixed control region towards the limiting current region of each process represented by reactions (2) and (3). The change of direction in each process generally occurs at similar potential for all rotation rates, although the potential shifts slightly to negative values for the $\mathrm{Cu}(\mathrm{I}) \rightarrow \mathrm{Cu}(0)$ process. This maximum is the point of inflexion and the point at which the mass transport effects begin to influence the reaction rate. The following area at the left of each peak in Fig. 5, corresponds to the limiting current region in both processes $\mathrm{Cu}(\mathrm{II}) \rightarrow \mathrm{Cu}(\mathrm{I})$ and $\mathrm{Cu}(\mathrm{I}) \rightarrow \mathrm{Cu}(0)$ and the region at which the derivative should be zero. It can be seen that the limiting current region corresponding to $\mathrm{Cu}$ (II) $\rightarrow \mathrm{Cu}$ (I) is easily identifiable; the derivatives at all rotation rates are close to zero. In the case of the $\mathrm{Cu}(\mathrm{I}) \rightarrow \mathrm{Cu}(0)$ process, the limiting current region is derived over a shorter potential range and the first derivative reaches a minimum but is never zero because the plateau region, shown in Fig. 2, is not horizontal. The limiting current value can be taken at the minimum value of $|\mathrm{d} I / \mathrm{d} E|$ on each curve. This method is sufficient when the plateau region is horizontal but when the limiting current region presents an ill-defined plateau the method is as reliable as methods 1 and 2 .

\subsection{Plots of the resistance, E/I, vs. the reciprocal of the current, $I^{-1}$}

This method involves plotting $E / I$ vs. $I^{-1}$ values calculated from the data of the $I$ vs. $E$ curve. The procedure has been used to estimate the limiting current of the reduction of 


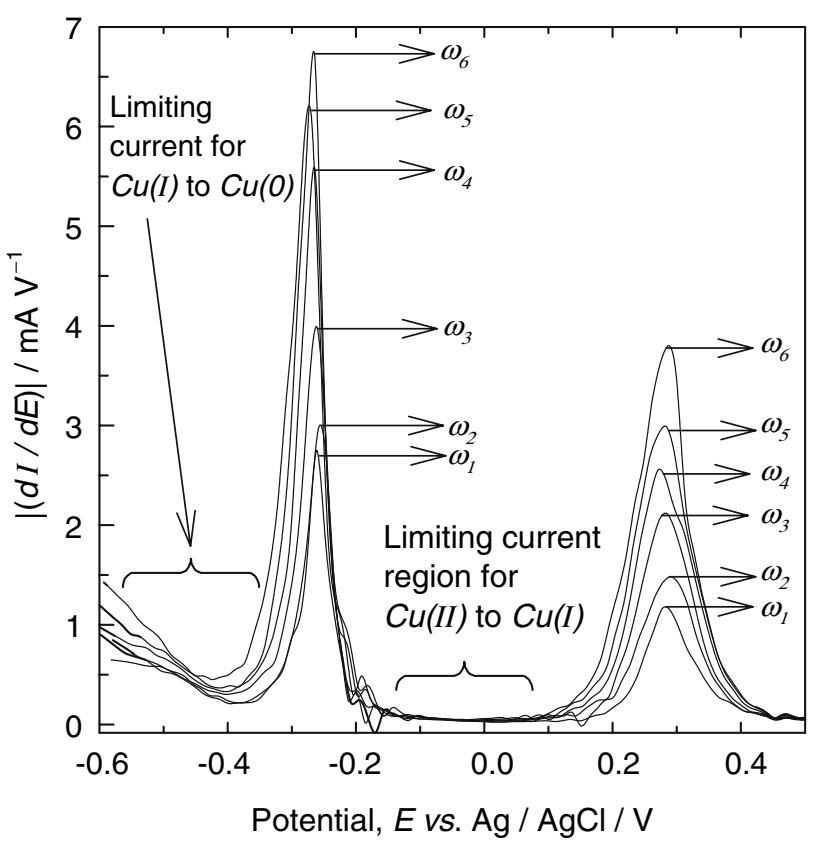

Fig. 5 Curves of the absolute value of $\mathrm{d} E / \mathrm{d} I$ vs. the applied potential, $E$, for the reduction of $\mathrm{Cu}(\mathrm{II})$ to $\mathrm{Cu}(0)$ at a platinum RDE using various rotation rates: $\omega_{1}=16, \omega_{2}=36, \omega_{3}=64, \omega_{4}=100$, $\omega_{5}=144$ and $\omega_{6}=196 \mathrm{rad} \mathrm{s}^{-1}$ (Data corresponds to Fig. 2)

$\mathrm{Cu}(\mathrm{II})$ to $\mathrm{Cu}(0)$ on a 100 ppi rotating cylinder electrode fabricated from reticulated vitreous carbon [27] and in other electrochemical systems [24, 28].

Plotting $E / I$ vs. $I^{-1}$ produces a curve with two sections corresponding to reactions (2) and (3), respectively. Each section consists of three zones separated by turning points where the slope of the curve changes sign or direction. Figure 6 shows the $E / I$ vs. $I^{-1}$ curve for a rotation rate of

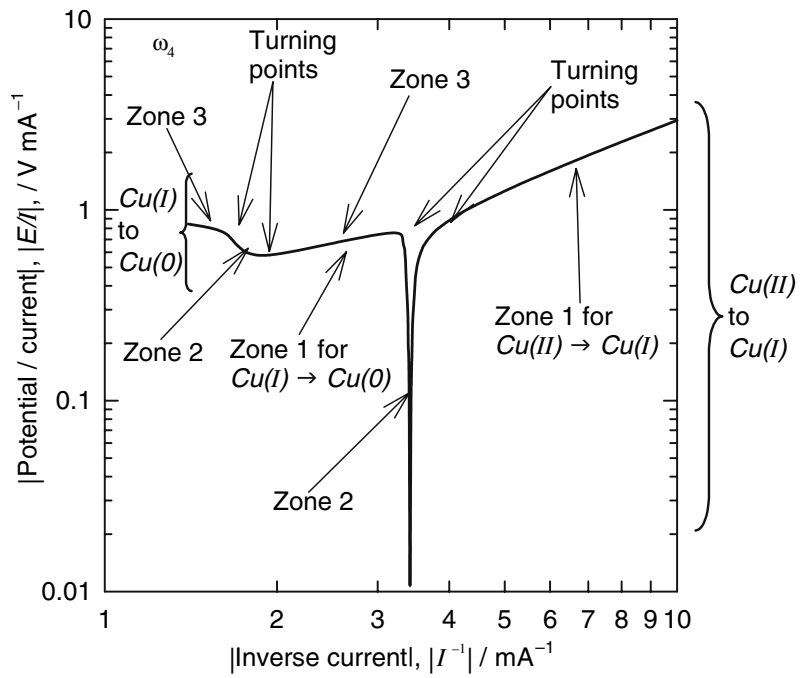

Fig. 6 Curve of $E / I$ vs. $I^{-1}$ for the reduction of $\mathrm{Cu}(\mathrm{II})$ to $\mathrm{Cu}(0)$ at a $\mathrm{Pt}$ RDE with $\omega_{1}=16 \mathrm{rad} \mathrm{s}^{-1}$. The curve shows the three zones and two turning points generated for each process $\omega_{4}=100 \mathrm{rad} \mathrm{s}^{-1}$ (from Fig. 2) where the zones and turning points for reactions (2) and (3) are indicated. In the first zone the current is small, both terms $E / I$ and $I^{-1}$ are large and the curve is steep. Zone two occurs when the curve approaches the limiting current region, the current becomes constant and the slope of the curve changes sign after the first turning point. A peak is observed if the limiting current region is completely horizontal (process $\mathrm{Cu}(\mathrm{II}) \rightarrow \mathrm{Cu}(\mathrm{I}))$. This is not always the case since the main reaction is often accompanied by a secondary reaction and often other complications such as $I R$ drop and charge transfer effects exist. The zone two as shown in the figure for the $\mathrm{Cu}(\mathrm{I}) \rightarrow \mathrm{Cu}(0)$ process is more commonly found. Zone three arises when the potential and the current increase beyond the limiting current region; the sign or direction of the slope changes again at the second turning point and both terms $E / I$ and $I^{-1}$ become smaller making the curve very steep again. It should be noted that in this case, zone 3 of the $\mathrm{Cu}(\mathrm{II}) \rightarrow \mathrm{Cu}(\mathrm{I})$ process is also zone 1 for the $\mathrm{Cu}(\mathrm{I}) \rightarrow \mathrm{Cu}(0)$ process, since this reaction is the secondary reaction of the first reduction process. The changes in the sign of the slope in this zone depend on whether the $E / I$ vs. $I^{-1}$ curve includes data of the secondary reaction or not. Since the values of $E / I$ and $I^{-1}$ at both sides of the limiting current region are both very large and very small, it is best to plot the data as the logarithmic of the absolute values in order to visualise the limiting current region.

Figure 7 shows the plot of the absolute values of $E / I$ vs. $I^{-1}$ (on logarithmic scales) for the family of curves shown earlier in Fig. 2 for the reduction of $\mathrm{Cu}(\mathrm{II})$ to $\mathrm{Cu}(0)$. As explained above, the reduction of $\mathrm{Cu}$ (II) to $\mathrm{Cu}$ (I) shows a minimum whereas the reduction of $\mathrm{Cu}(\mathrm{I})$ to $\mathrm{Cu}(0)$ is seen as an inflection in an S-shaped curve. The minimum peak observed for the first process, $\mathrm{Cu}(\mathrm{II}) \rightarrow \mathrm{Cu}(\mathrm{I})$ can be explained from the analysis of the $E / I$ vs. $I^{-1}$ curve. Considering that $E=f(I)$, the following relationship can be obtained [24]:

$\frac{\mathrm{d}(E / I)}{\mathrm{d}(1 / I)}=-I\left[\left(\frac{\mathrm{d}(I)}{\mathrm{d}(E)}\right)^{-1}-\frac{E}{I}\right]$

at the lowest point of the $E / I$ vs. $I^{-1}$ curve, the value of $\mathrm{d}(I) / \mathrm{d}(E)$ is sufficiently low for the term in square brackets in Eq. 6 to be zero, corresponding to the limiting current for the reduction of $\mathrm{Cu}(\mathrm{II})$ to $\mathrm{Cu}(\mathrm{I})$; the current values at the minimum peak observed on the curves of Fig. 7 are the limiting current values for this process. The reduction of $\mathrm{Cu}(\mathrm{I})$ to $\mathrm{Cu}(0)$, presents a plateau region that is influenced by the secondary reaction (see Fig. 2) and therefore the limiting current region is not seen as a peak but as an illdefined plateau region in Fig. 7. The limiting current for the $\mathrm{Cu}(\mathrm{I}) \rightarrow \mathrm{Cu}(0)$ process is determined as the halfway 
Fig. 7 The absolute value of $E /$ $I$ vs. $I^{-1}$ (logarithmic scales) for the reduction of $\mathrm{Cu}$ (II) to $\mathrm{Cu}(0)$ at a platinum $\mathrm{RDE}$ using various rotation rates

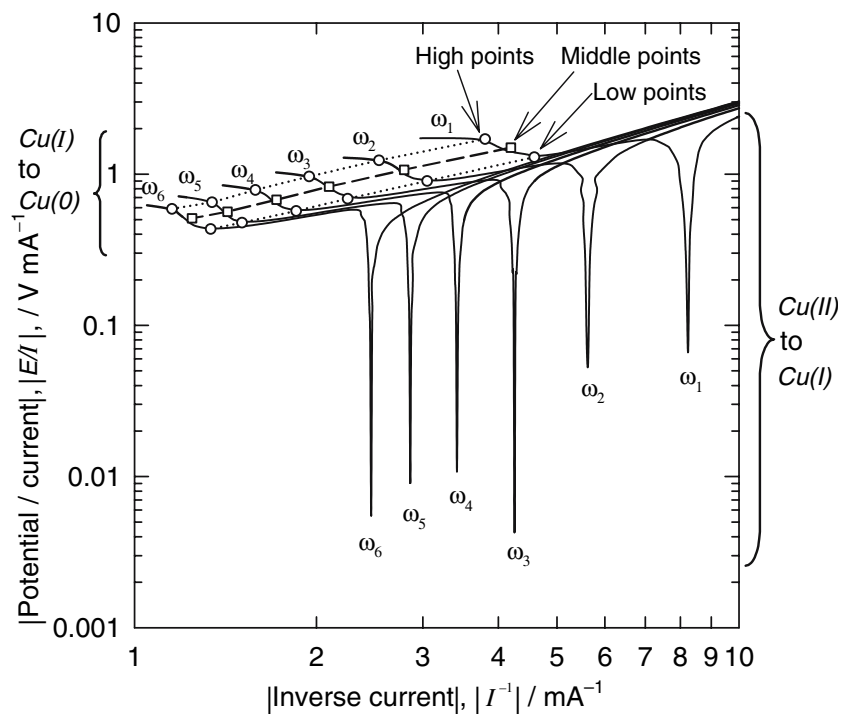

Figure 9 shows the low, middle and high points determined from the current potential curves for reactions (2) and (3). For $\mathrm{Cu}(\mathrm{II}) \rightarrow \mathrm{Cu}(0)$, the sharp low peak and the middle points are very close except at the highest rotation rates, where the middle point appears at more negative potentials. The high point appears at the end of the plateau region. For the $\mathrm{Cu}(\mathrm{I}) \rightarrow \mathrm{Cu}(0)$ process, the low, middle and high points can be clearly distinguished. The differences between the current indicated by the middle point and the line of the $I$ vs. $E$ are slightly larger as the rotation rate increases.

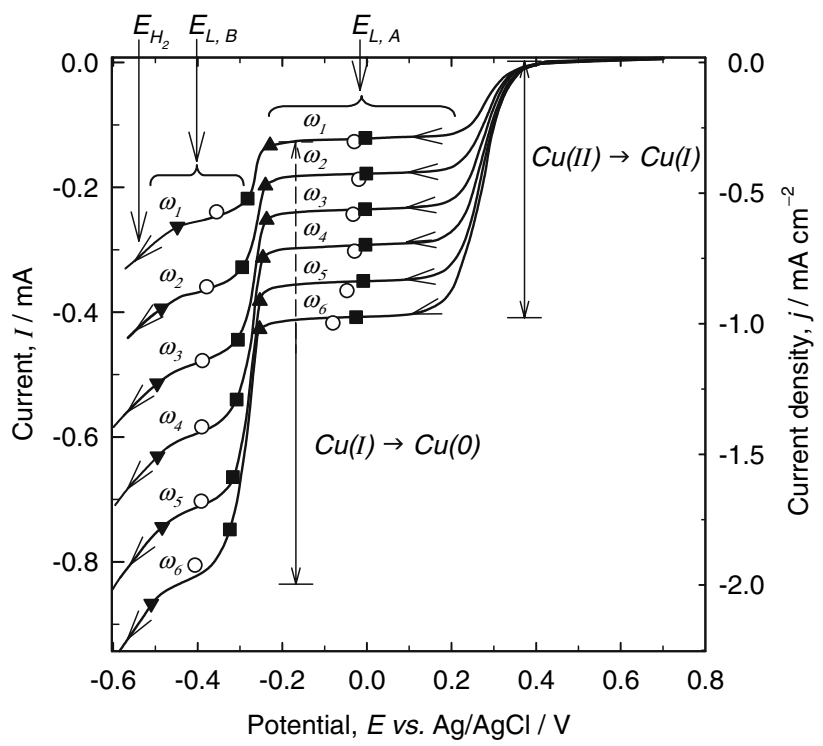

Fig. 9 Reduction of $2 \times 10^{-3} \mathrm{~mol} \mathrm{dm}^{-3} \mathrm{CuCl}_{2}$ in $1.5 \mathrm{~mol} \mathrm{dm}^{-3}$ $\mathrm{NaCl}$ at $\mathrm{pH} 2$ at a Pt RDE with a potential sweep rate of $10 \mathrm{mV} \mathrm{s}^{-1}$ and at $20^{\circ} \mathrm{C}$. $\mathrm{Cu}(\mathrm{II}) \rightarrow \mathrm{Cu}(\mathrm{I}): \mathbf{\square}$ low, o middle and $\boldsymbol{\Delta}$ high points. $\mathrm{Cu}(\mathrm{I}) \rightarrow \mathrm{Cu}(0):-\boldsymbol{\square}$ low, $\circ$ middle and $\boldsymbol{\nabla}$ high points. Rotation rates: $\omega_{1}=16, \omega_{2}=36, \omega_{3}=64, \omega_{4}=100, \omega_{5}=144$ and $\omega_{6}=196 \mathrm{rad} \mathrm{s}^{-1}$ 
Table 1 Limiting current values from four methods

\begin{tabular}{|c|c|c|c|c|c|}
\hline \multirow[t]{3}{*}{ Rotation rate, $\omega\left(\mathrm{rad} \mathrm{s}^{-1}\right)$} & \multicolumn{5}{|c|}{ Limiting current, $I_{\mathrm{L}}(\mathrm{mA})$} \\
\hline & \multicolumn{5}{|l|}{ Method } \\
\hline & (1) Direct & (2) $\Delta E / 2$ & (3) Derivative & (4) $E / I$ vs. $I^{-1}$ & Theoretical value \\
\hline$\omega_{1}=16$ & -0.119 & -0.121 & -0.121 & -0.127 & -0.112 \\
\hline$\omega_{2}=36$ & -0.178 & -0.177 & -0.178 & -0.187 & -0.169 \\
\hline$\omega_{3}=64$ & -0.235 & -0.235 & -0.235 & -0.243 & -0.225 \\
\hline$\omega_{4}=100$ & -0.293 & -0.294 & -0.292 & -0.302 & -0.281 \\
\hline$\omega_{5}=144$ & -0.350 & -0.351 & -0.350 & -0.366 & -0.337 \\
\hline$\omega_{6}=196$ & -0.408 & -0.407 & -0.408 & -0.417 & -0.394 \\
\hline
\end{tabular}

$\mathrm{Cu}(\mathrm{II}) \rightarrow \mathrm{Cu}(\mathrm{I})$ reaction in $1.5 \mathrm{~mol} \mathrm{dm}{ }^{-3} \mathrm{NaCl}, \mathrm{pH} 2$ and $20{ }^{\circ} \mathrm{C}$ at a $\mathrm{Pt} \mathrm{RDE}$ (area $=0.42 \mathrm{~cm}^{2}$ ) at various rotation rates and a potential sweep rate of $10 \mathrm{mV} \mathrm{s}^{-1}$. The theoretical values assume $D_{\mathrm{Cu}(\mathrm{II})}=4.3 \times 10^{-6} \mathrm{~cm}^{2} \mathrm{~s}^{-1}$

Table 2 Limiting current values from various methods for $\mathrm{Cu}(\mathrm{I}) \rightarrow \mathrm{Cu}(0)$ in $1.5 \mathrm{~mol} \mathrm{dm}{ }^{-3} \mathrm{NaCl}, \mathrm{pH} 2$ at $20{ }^{\circ} \mathrm{C}$ at a $\mathrm{Pt} \mathrm{RDE}\left(\operatorname{area}=0.42 \mathrm{~cm}^{2}\right)$ at various rotation rates and a potential sweep rate of $10 \mathrm{mV} \mathrm{s}^{-1}$

\begin{tabular}{|c|c|c|c|c|c|}
\hline \multirow[t]{3}{*}{ Rotation rate, $\omega\left(\mathrm{rad} \mathrm{s}^{-1}\right)$} & \multicolumn{5}{|c|}{ Limiting current, $I_{\mathrm{L}}(\mathrm{mA})$} \\
\hline & \multicolumn{5}{|l|}{ Method } \\
\hline & (1) Direct & (2) $\Delta E / 2$ & (3) Derivative & (4) $E / I$ vs. $I^{-1}$ & Theoretical value \\
\hline$\omega_{1}=16$ & -0.250 & -0.252 & -0.258 & -0.239 & -0.232 \\
\hline$\omega_{2}=36$ & -0.361 & -0.363 & -0.369 & -0.359 & -0.348 \\
\hline$\omega_{3}=64$ & -0.475 & -0.478 & -0.477 & -0.478 & -0.464 \\
\hline$\omega_{4}=100$ & -0.589 & -0.598 & -0.595 & -0.584 & -0.580 \\
\hline$\omega_{5}=144$ & -0.709 & -0.715 & -0.710 & -0.703 & -0.696 \\
\hline$\omega_{6}=196$ & -0.825 & -0.829 & -0.820 & -0.805 & -0.812 \\
\hline
\end{tabular}

The theoretical values assume $D_{\mathrm{Cu}(\mathrm{I})}=4.3 \times 10^{-6} \mathrm{~cm}^{2} \mathrm{~s}^{-1}$

In this method the changes of sign of the slope in the $E / I$ vs. $I^{-1}$ curve allows the limiting current to be determined in a relatively objective fashion, leading to easy identification of the limiting current region. The method is reliable when ill-defined plateau regions are present. Using this method it appears that a clearer distinction of the limiting current region can be seen when the secondary reaction shows large currents in a short potential range. In the extreme case of a very poorly defined plateau region, the method does not provide a clear distinction of the limiting current region; this situation will be analysed in a further paper [29].

\section{Comparison of methods}

The limiting current values calculated using the four methods described above and the theoretical limiting current calculated from the Levich equation are presented in Tables 1 and 2 at the various rotation rates used in the reduction of $\mathrm{Cu}(\mathrm{II})$ ions to $\mathrm{Cu}(\mathrm{I})$, and for the reduction of $\mathrm{Cu}(\mathrm{I})$ to $\mathrm{Cu}(0)$, respectively. In general, the limiting current values obtained for the $\mathrm{Cu}(\mathrm{II}) \rightarrow \mathrm{Cu}(\mathrm{I})$ process from the

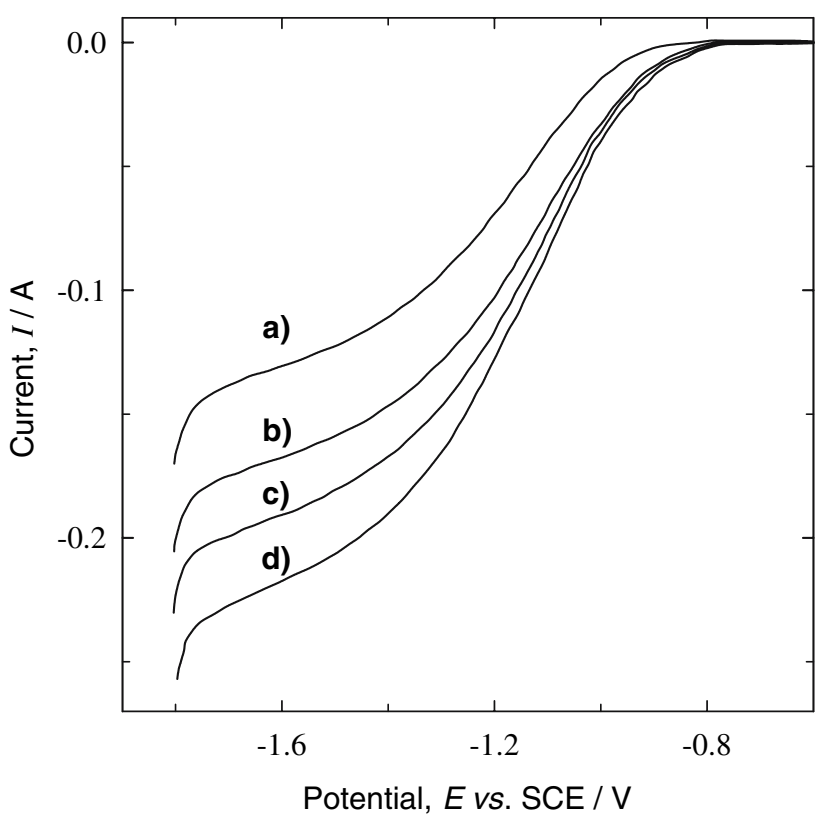

Fig. 10 Current vs. potential curves for the reduction of $1 \times 10^{-2} \mathrm{~mol}$ $\mathrm{dm}^{-3}$ of ferricyanide ion in $1 \mathrm{~mol} \mathrm{dm}^{-3} \mathrm{NaOH}$ at a 10 ppi RVC electrode in the FM01-LC electrolyser at $T=25^{\circ} \mathrm{C}$. Mean linear flow velocities: (a) 6.2 , (b) 10.6 , (c) 15.0 and (d) $19.5 \mathrm{~cm} \mathrm{~s}^{-1}$ 
Table 3 Limiting current values from various methods for $1 \times 10^{-2} \mathrm{~mol} \mathrm{dm}^{-3}$ of ferricyanide $1 \mathrm{~mol} \mathrm{dm}^{-3} \mathrm{NaOH}$ at a 60 ppi RVC electrode at various mean linear flow velocities $\left(T=25^{\circ} \mathrm{C}\right)$

\begin{tabular}{lllll}
\hline $\begin{array}{l}\text { Mean linear flow } \\
\text { rate, } v\left(\mathrm{~cm} \mathrm{~s}^{-1}\right)\end{array}$ & \multicolumn{4}{l}{ Limiting current, $I_{\mathrm{L}}(\mathrm{mA})$} \\
\cline { 2 - 5 } & Method & (2) $\Delta E / 2$ & (3) Derivative & (4) $E / I$ vs. $I^{-1}$ \\
\cline { 2 - 4 } & (1) Direct & -127 & -134 & -130 \\
\hline 6.20 & -127 & -166 & -169 & -165 \\
10.6 & -164 & -192 & -191 & -192 \\
15.0 & -185 & -222 & -214 & -219 \\
19.5 & -214 & & & \\
\hline
\end{tabular}

first three methods differ within 1-2\% (which is within the operational value margin) while the values obtained by the fourth method are slightly larger by an average of 5\%. The limiting current values from all the methods are larger than the calculated theoretical values; the first three methods are higher by $6-8 \%$ while the fourth method by $6-13 \%$. For the $\mathrm{Cu}(\mathrm{I}) \rightarrow \mathrm{Cu}(0)$ process, the values obtained from the direct, the $E_{\max }$ and $E_{\min }$ and the derivative methods are also within $1-2 \%$ of each other but the $E / I$ vs. $I^{-1}$ method produce values approximately 5\% lower except for the rotation rates at $\omega_{4}$ and $\omega_{6}$ where the current values between the methods are very close. Again, the values produced by the first three methods are larger than the theoretical value by approximately $2-8 \%$ while the fourth method produces values closer to the theoretical by $0-3 \%$.

\section{Limiting current for the $\mathrm{Fe}(\mathrm{CN})_{6}^{-3} / \mathrm{Fe}(\mathrm{CN})_{6}^{-4}$ system}

Figure 10 shows the $I$ vs. $E$ curve for the reduction of ferricyanide ion on a 10 pore per inch (ppi) reticulated vitreous carbon (RVC). The limiting current region in these curves is not easy to distinguish due to IR drop through the 3 -D porous electrode and the evolution of hydrogen. The system behaves in a similar fashion to the $\mathrm{Cu}(\mathrm{I}) / \mathrm{Cu}(0)$ process were the limiting current region is affected by a secondary reaction. Table 3 shows a comparison of limiting current values obtained by application of the four methods outlined above for the copper system: direct estimation, using $E_{\max }$ and $E_{\min }$, the derivative, $\mathrm{d} I / \mathrm{d} E$ and the resistance $E I^{-1}$ vs. the reciprocal of the current, $I^{-1}$ (Fig. 11).

The values in the table show that the four methods provide similar limiting current values at low mean linear flow rates. Larger differences can be observed at the highest velocity where the $E I^{-1}$ vs. $I^{-1}$ method provides a middle value of limiting current between the direct and derivative methods and the $\Delta E$ method. Since the evaluation of the limiting current via the direct and $\Delta E$ methods depends on the ability and skills of the investigator the advantage of the $E / I^{-1}$ vs. $I^{-1}$ method in this case is to provide a reliable systematic procedure to calculate the limiting current.

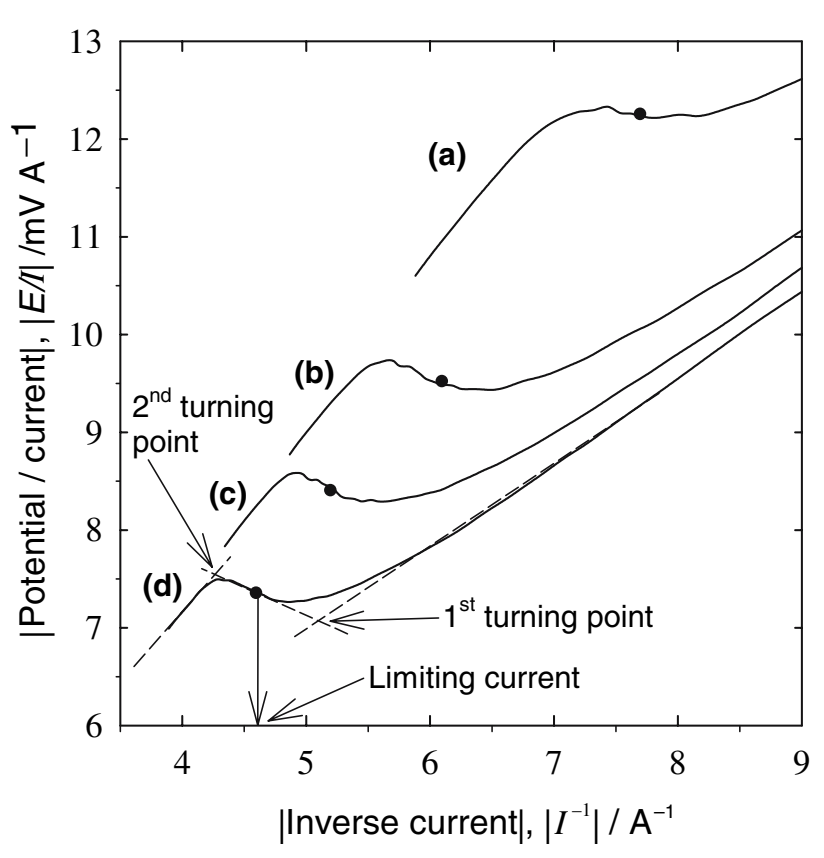

Fig. 11 Resistance $E / I^{-1}$ vs. the reciprocal of the current $I^{-1}$ obtained from the current potential curves of Fig. 10. Mean linear flow velocities: (a) 6.2 , (b) 10.6, (c) 15.0 and (d) $19.5 \mathrm{~cm} \mathrm{~s}^{-1}$. The full dotted points $(-)$ in each curve indicate the middle point between the first and second turning points, i.e., the limiting current as indicated in the curve for the mean linear flow velocity (d), $19.5 \mathrm{~cm} \mathrm{~s}^{-1}$

\section{Conclusions}

A. If the limiting current region is well defined, the direct, $E_{\max }$ and $E_{\min }$ and derivative methods, produce similar values of limiting current close to the theoretical value for the $\mathrm{Cu}(\mathrm{II}) / \mathrm{Cu}(0)$ system. The method proposed in this paper, using a plot of $E / I$ vs. $I^{-1}$, can produce values approximately $6-13 \%$ higher.

B. If the limiting current region is ill-defined (i.e., affected by $I R$ drop or secondary reactions) the direct, the $E_{\max }$ and $E_{\min }$ and the derivative methods show similar limiting current but ones which are higher than the theoretical value by $2-8 \%$ for the copper system. The method proposed here, $E / I$ vs. $I^{-1}$, produces limiting current values close to the theoretical value (with measured values typically between 0 and 3\% from the theoretical value). 
C. The $E / I$ vs. $I^{-1}$ curves offer a clear and systematic methodology to reveal the limiting current region when $I R$ drop and secondary reactions make the limiting current determination difficult.

D. The $E / I$ vs. $I^{-1}$ method produces close limiting current values to the theoretical when the limiting current plateau is affected by IR drop and secondary reactions. When the plateau is well defined this method produces higher limiting current values than the first three methods shown in this paper. The method allows for a clear estimation of the potential limits of the diffusion controlled region.

\section{References}

1. Scannell RA, Walsh FC (1989) I Chem E Symp Ser 112:59

2. Pletcher D, Walsh FC (1990) Industrial Electrochemistry, 2nd edn. Chapman and Hall London, p. 81, 114

3. Walsh FC (1993) A First Course in Electrochemical Engineering. The Electrochemical Consultancy, Romsey, p 104

4. Bard AJ, Faulkner LR (2001) Electrochemical methods: fundamentals and applications, 2nd edn. Wiley, New York

5. Wragg AA, Leontaritis AA (1991) In: Electrochemical cell design and optimization. Dechema monograph, vol 123, p 345

6. Wragg AA, Leontaritis AA (1997) Chem Eng J 66:1

7. Krýsa J, Reuter W, Wragg AA (2005) Int J Heat Mass Trans 48:2323

8. Chai D, Genders D, Weinberg N, Zappi G, Bernasconi E, Lee J, Roletto J, Sogli L, Walker D, Martin C, Menon V, Zelenay P, Zhang H (2002) Org Process Res Dev 6:178
9. Hammond JK, Robinson D, Walsh FC (1991) In: Kreysa G (ed) Electrochemical cell design and optimization procedures. Dechema monographs, vol 123. Wiley-VCH, Frankfurt, p 279-297

10. Hall D, Scott K, Jachuck RJJ (2001) Int J Heat Mass Tran 44:2201

11. Burns JR, Jachuck RJ (2005) Int J Heat Mass Tran 48:2540

12. Valerdi-Peréz R, Ibañez-Mengual JA (2001) Desalination 141:23

13. Tanaka Y (2005) J Memb Sci 266:6

14. Tzanetakis N, Taama WM, Scott K, Jachuck RJJ, Slade RS, Varcoe J (2003) Separ Purif Tech 30:113

15. Barton SC, West AC (2001) J Electrochem Soc 148:A490

16. Dubbe A (2003) Sensor Actuator B Chem 88:138

17. Levich B (1947) Discuss Faraday Soc 1:37

18. Selman JR, Tobias CW (1978) Adv Chem Eng 10:211

19. Tobias CW, Eisenberg M, Wilke CR (1952) J Electrochem Soc 99:C359

20. Ponce de León C, Walsh FC (2003) Trans Inst Met Fin 81:B9

21. Brown CJ, Pletcher D, Walsh FC, Hammond JK, Robinson D (1992) J Appl Electrochem 22:613

22. Brown CJ, Pletcher D, Walsh FC, Hammond JK, Robinson D (1993) J Appl Electrochem 23:38

23. Griffiths M, Ponce de León C, Walsh FC (2005) AIChE J 51:682

24. Ponce de León C, Field RW (2000) J Appl Electrochem 30:1087

25. IUPAC Compendium of Chemical Technology, 57 (1985) 1502

26. Gabe DR, Makanjuola PA (1986) In: Electrochemical engineering. I Chem E symposium series vol 98, p 309

27. Reade GW, Ponce de León C, Walsh FC (2006) Electrochim Acta 51:2728

28. Brown IJ, Sotiropoulos S (2001) J Appl Electrochem 31:1203

29. Low TCJ, Ponce de León C, Kerr C, Walsh FC. To be submitted to Electrochim Acta 